\title{
Global chemokine expression in methylmercury-treated mice: methylmercury induces brain-specific expression of CCL3 and CCL4
}

\author{
Min-Seok Kim¹, Tsutomu Takahashi' ${ }^{1}$, Jin-Yong Lee ${ }^{1,2}$, Gi-Wook Hwang ${ }^{1}$ \\ and Akira Naganuma ${ }^{1}$ \\ ${ }^{1}$ Laboratory of Molecular and Biochemical Toxicology, Graduate School of Pharmaceutical Sciences, \\ Tohoku University, Aoba-ku, Sendai 980-8578, Japan \\ ${ }^{2}$ Laboratory of Pharmaceutical Health Sciences, School of Pharmacy, Aichi Gakuin University, \\ 1-100 Kusumoto, Chikusa-ku, Nagoya 464-8650, Japan
}

(Received September 25, 2013; Accepted October 22, 2013)

\begin{abstract}
We previously reported that methylmercury induces brain-specific upregulation of a chemokine gene, the CCL4 gene. In this study, we investigated the changes in gene expression levels of all chemokines in various tissues (cerebellum, cerebrum, kidney, liver, and spleen) of methylmercurytreated mice. We found that methylmercury induced upregulation of the CCL4 gene and the CCL3 gene, in a brain-specific manner. This finding suggests that upregulation of these two chemokine genes mediates selective damage by methylmercury in the central nervous system.
\end{abstract}

Key words: Methylmercury, Chemokine, Induction, Brain, CCL3, CCL4

\section{INTRODUCTION}

Methylmercury is an environmental toxicant that selectively damages the central nervous system (CNS), but the mechanism of its toxicity has been unclear (Castoldi et al., 2003). We recently reported that administration of methylmercury induces brain-specific upregulation of a chemokine gene, the CCL4 gene (Hwang et al., 2011; Lee et al., 2012). Chemokines, a family of chemotactic cytokines, are secreted mainly by immune cells and play a role in inflammation (Murdoch and Finn, 2000). To date, 37 chemokines have been identified in mice and are classified into four subfamilies $(\mathrm{C}, \mathrm{CC}, \mathrm{CXC}$ and CX3C) based on their structural characteristics (Giraud et al., 2010; Ito et al., 2006). Recently, it was revealed that chemokines are secreted in several organs, including the brain, kidney, and liver, in addition to immune cells (Gorter et al., 2006; Shimizu et al., 2012; Soria and Ben-Baruch, 2008).

In this study, with the aim of identifying the chemokines that are upregulated in a brain-specific manner in response to methylmercury administration, we employed a mouse model to examine methylmercury-induced changes in comprehensive chemokine expression profiles in various tissues.

\section{MATERIALS AND METHODS}

\section{Animal experiments}

C57BL/6 male mice (8 weeks old) were purchased from Japan SLC, Inc. (Shizuoka, Japan) and housed in plastic cages ( 4 animals per cage) at $22 \pm 2{ }^{\circ} \mathrm{C}$ with a relative humidity of $55 \pm 20 \%$ under a 12-hr light/dark cycle. Chow (F-2, Oriental Yeast, Tokyo, Japan) and water were provided ad libitum. All experiments were performed in accordance with the Regulations for Animal Experiments and Related Activities at Tohoku University. After an adaptation period, mice were randomly divided into control $(\mathrm{n}=5)$ and methylmercury-treated $(\mathrm{n}=5)$ groups. Methylmercuric chloride dissolved in physiological saline was administered by subcutaneous injection.

\section{Measurement of chemokine mRNA levels by quantitative real-time PCR}

Total RNA was isolated from tissues using the Isogen Kit (Nippon Gene, Tokyo, Japan) according to the manufacturer's protocol. First-strand cDNA synthesis was carried out using the PrimeScript ${ }^{\mathrm{TM}}$ RT Reagent Kit (Takara,

Correspondence: Akira Naganuma (E-mail: naganuma@m.tohoku.ac.jp) 
Shiga, Japan) (Kim et al., 2012). Quantitative real-time PCR was performed using SYBR Premix EX Taq (Takara) and a Thermal Cycler Dice ${ }^{\circledR}$ (Takara) with the oligonucleotides shown in Table 1. Fold changes in mRNA levels were determined from standard curves after calibrating the assay.

\section{RESULTS AND DISCUSSION}

Methylmercuric chloride $(10 \mathrm{mg} / \mathrm{kg}$ ) was administered by subcutaneous injection once daily for 7 consecutive days. The cerebellum, cerebrum, kidney, liver, and spleen were removed $24 \mathrm{hr}$ after the final administration, and changes in the gene expression levels of 37 chemokines (see Table 1) were investigated in each of the tissues. Expression levels of the following chemokine genes were significantly upregulated ( $\geq 5$-fold) by methylmercury: in the cerebellum, CCL2, CCL3, CCL4, CCL5, CCL7, CCL9, CCL12, CXCL5, and CXCL10; in the cerebrum, CCL2, CCL3, CCL4, CCL7, CCL11, CCL12, CCL17, and CXCL10; in the liver, CCL6 and CXCL14; and in the kidney, CCL2, CCL7, CCL9, CCL12, CXCL1, CXCL2, CXCL3, CXCL5, and CXCL17 (Table 2). Methylmercury did not significantly increase the upregulation of any of the tested chemokine genes in the spleen (Table 2). Taken together, the 7-day administration of methylmercury appeared to upregulate CCL4, as well as CCL3 and CXCL10, in a brain-specific manner in mice.

When we examined the time-course changes in the expression levels of the CCL3, CCL4, and CXCL10 genes over the 7-day regimen, on day 5 of administration, CXCL10 gene expression was significantly increased in the kidney and there was evidence of significant brainspecific changes in CCL3 and CCL4 expression levels, but no upregulation was seen in the other organs at any of the time points tested (Fig. 1). Furthermore, when the expression levels of the CCL3 and CCL4 genes were examined 5 days after a single administration of various doses of methylmercury, both were found to be increased in a dose-dependent manner in the cerebellum and cerebrum (Fig. 2). CCL3 and CCL4 are known as macrophage inflammatory protein (MIP) $1 \alpha$ and MIP $1 \beta$, respectively, and both bind to the chemokine receptor CCR5, thereby activating downstream signal pathways (Gamo et al., 2008; Rollins, 1997). CCL3 and CCL4 are also reported to be upregulated after brain injury (Redell et al., 2013). Therefore, we cannot deny the possibility that excessive activation of signal pathways downstream of CCR5 mediates, via methylmercury-induced brain-specific upregulation of CCL3 and CCL4, methylmercury's toxicity in the CNS.
Table 1. Oligonucleotides primers used for quantitative real-time PCR.

\begin{tabular}{|c|c|c|}
\hline Gene & Sense & Antisense \\
\hline CCL1 & ggatgttgacagcaagagca & tagttgaggcgcagctttct \\
\hline CCL2 & ttgtcaccaagctcaagagaga & gaggtggttgtggaaaaggtag \\
\hline CCL3 & atgaaggtctccaccactgc & cccaggtctctttggagtca \\
\hline CCL4 & caaacctaaccccgagcaacac & ggtctcatagtaatccatcacaaagc \\
\hline CCL5 & cectcaccatcatcctcact & ccttcgagtgacaaacacga \\
\hline CCL6 & aggctggectcatacaagaa & tcccetcctgctgataaaga \\
\hline CCL7 & aatgcatccacatgctgcta & ctttggagttggggttttca \\
\hline CCL8 & ttctttgcetgctgctcata & tctggaaaaccacagcttcc \\
\hline CCL9 & tgtttcacatgggctttcaa & ttgtaggtccgtggttgtga \\
\hline CCL11 & tccacagcgettctattcct & ctatggctttcagggtgcat \\
\hline CCL12 & gtcctcaggtattggctgga & gggtcagcacagatctcctt \\
\hline CCL17 & tgcttctggggacttttctg & tggccttcttcacatgtttg \\
\hline CCL19 & agactgctgcctgtctgtga & gcctttgttcttggcagaag \\
\hline CCL20 & cgactgttgectctcgtaca & aggaggttcacagecctttt \\
\hline CCL22 & gctctcgtccttcttgctgt & gcaggattttgaggtccaga \\
\hline CCL24 & ctgtgaccatccectcatct & tatgtgcctctgaacccaca \\
\hline CCL25 & ctgggttaccagcacaggat & ctcatcgecetcttcacatt \\
\hline CCL26 & ttgttctcetggecatcttc & tcactggtgcagctcttgtc \\
\hline CCL27 & tgtctccaacaagccagaga & gacagcctggaggtgacagt \\
\hline CCL28 & gttcatgcagcatccagaga & cctgtgtgttccacgtgttc \\
\hline CXCL1 & gctgggattcacctcaagaa & tggggacaccttttagcatc \\
\hline CXCL2 & agtgaactgcgctgtcaatg & ttcagggtcaaggcaaactt \\
\hline CXCL3 & agtgcctgaacacctacca & ggacttgecgetcttcagta \\
\hline CXCL4 & agtcctgagctgctgcttct & ggcaaattttcctcccattc \\
\hline CXCL5 & tgcccettcctcagtcatag & gtgcattccgettagctttc \\
\hline CXCL7 & tgggcttcagactcagacct & tcctggectgtacacattca \\
\hline CXCL9 & ttttcctcttgggcatcatc & agtccggatctaggcaggtt \\
\hline CXCL10 & aagtgctgccgtcattttct & gtggcaatgatctcaacacg \\
\hline CXCL11 & agctgctcaaggcttcctta & ctgcattatgaggcgagctt \\
\hline CXCL12 & gctctgcatcagtgacggta & taatttcgggtcaatgcaca \\
\hline CXCL13 & tctggaagcccattacacaa & tttgtaaccatttggcacga \\
\hline CXCL14 & aagctggaaatgaagccaaa & cttctcgttccaggcattgt \\
\hline CXCL15 & ccatgggtgaaggctactgt & tagaggtctcccgaattgga \\
\hline CXCL16 & gggaagagttttcaccacca & ggttgggtgtgctctttgtt \\
\hline CXCL17 & tgttgcttccagtgatgctc & gctgtggettttctctttgg \\
\hline $\mathrm{XCL} 1$ & tgactttcctgggagtctgc & catttggcttctggatcagc \\
\hline CX3CL1 & gcagatccccagaaactgag & ggcaccaggacgtatgagtt \\
\hline GAPDH & atcaccatcttccaggagcga & aggggecatccacagtctt \\
\hline
\end{tabular}


Brain-specific induction of CCL3 and CCL4 by methylmercury

Table 2. Changes in mRNA levels of chemokines in various organs of methylmercury-treated mice.

\begin{tabular}{|c|c|c|c|c|c|c|}
\hline & & Cerebrum & Cerebellum & Liver & Kidney & Spleen \\
\hline \multirow[t]{20}{*}{ CC chemokines } & CCL1 & $3.54 \pm 2.00$ & $0.71 \pm 0.28$ & ND & $1.14 \pm 0.76$ & $0.70 \pm 0.44$ \\
\hline & CCL2 & $20.57 \pm 10.74 * *$ & $22.31 \pm 11.73^{*}$ & $1.25 \pm 0.57$ & $39.12 \pm 17.77 * *$ & $0.37 \pm 0.13 * *$ \\
\hline & CCL3 & $51.70 \pm 16.65^{* * *}$ & $75.34 \pm 44.42 * *$ & $1.42 \pm 0.30$ & $1.18 \pm 0.48$ & $1.53 \pm 0.82$ \\
\hline & CCL4 & $72.54 \pm 45.02 *$ & $70.39 \pm 22.63 * * *$ & $2.24 \pm 1.17$ & $1.89 \pm 0.71$ & $1.58 \pm 0.77$ \\
\hline & CCL5 & $2.46 \pm 1.09^{*}$ & $7.63 \pm 4.24^{*}$ & $4.18 \pm 1.06^{* *}$ & $4.16 \pm 3.07$ & $0.49 \pm 0.29^{*}$ \\
\hline & CCL6 & $1.81 \pm 0.62$ & $3.26 \pm 1.08 * *$ & $8.56 \pm 4.07 * *$ & $2.17 \pm 0.99^{*}$ & $2.35 \pm 0.72 * *$ \\
\hline & CCL7 7 & $14.03 \pm 7.71 * *$ & $10.13 \pm 5.89^{* *}$ & $5.51 \pm 2.93$ & $8.65 \pm 5.23^{*}$ & $0.22 \pm 0.09$ \\
\hline & CCL8 & $1.77 \pm 1.07$ & $1.62 \pm 0.59$ & $4.19 \pm 3.04$ & $0.95 \pm 0.70$ & $1.33 \pm 0.15$ \\
\hline & CCL9 & $3.63 \pm 1.99 *$ & $6.32 \pm 2.91 * *$ & $1.18 \pm 0.51$ & $7.65 \pm 2.94 * *$ & $2.89 \pm 1.07^{*}$ \\
\hline & CCL11 & $6.02 \pm 3.93^{*}$ & $3.32 \pm 1.01 * *$ & $0.34 \pm 0.23$ & $2.27 \pm 0.97$ & $0.57 \pm 0.29$ \\
\hline & CCL12 & $63.09 \pm 34.88^{* *}$ & $31.05 \pm 19.41 * *$ & $1.81 \pm 1.92$ & $11.36 \pm 9.65^{*}$ & $0.02 \pm 0.01 *$ \\
\hline & CCL17 & $5.68 \pm 2.54 * *$ & $2.82 \pm 0.68^{* *}$ & $1.03 \pm 0.66$ & $0.57 \pm 0.36$ & $2.32 \pm 1.96$ \\
\hline & CCL19 & $1.57 \pm 0.39^{*}$ & $1.38 \pm 0.24^{*}$ & $1.20 \pm 0.56$ & $0.59 \pm 0.23$ & $0.37 \pm 0.16^{* *}$ \\
\hline & CCL20 & $1.19 \pm 0.38$ & ND & ND & $4.47 \pm 2.65^{*}$ & ND \\
\hline & CCL22 & $2.22 \pm 0.37^{* *}$ & $1.95 \pm 0.77^{*}$ & $1.13 \pm 0.72$ & $1.01 \pm 0.79$ & $0.39 \pm 0.19^{* *}$ \\
\hline & CCL24 & $1.07 \pm 0.23$ & $1.17 \pm 0.57$ & $2.25 \pm 0.87^{*}$ & $0.81 \pm 0.36$ & $1.35 \pm 0.54$ \\
\hline & CCL25 & $1.17 \pm 0.32$ & $1.48 \pm 0.44$ & $0.52 \pm 0.37$ & $0.62 \pm 0.14 * *$ & $0.31 \pm 0.17$ \\
\hline & CCL26 & $0.80 \pm 0.33$ & $1.41 \pm 0.67$ & $2.63 \pm 1.36^{*}$ & $0.71 \pm 0.21$ & ND \\
\hline & CCL27 & $0.65 \pm 0.15^{* *}$ & $1.17 \pm 0.87$ & $0.98 \pm 0.35$ & $0.50 \pm 0.20 * *$ & $0.36 \pm 0.12 * * *$ \\
\hline & CCL28 & $1.17 \pm 0.48$ & $1.11 \pm 0.36$ & $1.41 \pm 0.35$ & $0.54 \pm 0.13 *$ & $0.09 \pm 0.01$ \\
\hline \multirow[t]{15}{*}{ CXC chemokines } & CXCL1 & $4.64 \pm 2.95$ & $7.60 \pm 5.79$ & $3.83 \pm 0.51^{* *}$ & $86.50 \pm 32.02 * * *$ & ND \\
\hline & CXCL2 & $4.37 \pm 2.48$ & $4.84 \pm 3.23$ & $3.70 \pm 2.80$ & $63.07 \pm 12.72 * * *$ & $1.11 \pm 1.09$ \\
\hline & CXCL3 & ND & ND & ND & $9.19 \pm 3.40^{* *}$ & ND \\
\hline & CXCL4 & $0.80 \pm 0.36$ & $0.82 \pm 0.29$ & $2.57 \pm 1.59$ & $4.69 \pm 1.29 * * *$ & $1.71 \pm 0.79$ \\
\hline & CXCL5 & $2.64 \pm 1.37 *$ & $12.72 \pm 5.89 * *$ & $0.78 \pm 0.56$ & $115.06 \pm 51.56^{*}$ & $1.47 \pm 0.30$ \\
\hline & CXCL7 & $7.50 \pm 6.82$ & $2.07 \pm 0.58$ & $2.76 \pm 1.29^{*}$ & $1.80 \pm 0.80$ & $1.92 \pm 0.64$ \\
\hline & CXCL9 & $0.86 \pm 0.82$ & $5.28 \pm 4.35$ & $0.57 \pm 0.34$ & $0.86 \pm 0.60$ & $0.79 \pm 0.48$ \\
\hline & CXCL10 & $50.59 \pm 28.52 *$ & $20.46 \pm 11.76^{*}$ & $0.47 \pm 0.21$ & $4.53 \pm 3.33$ & $0.69 \pm 0.44$ \\
\hline & CXCL11 & $0.62 \pm 0.27$ & $1.01 \pm 0.18$ & $0.76 \pm 0.19$ & $0.88 \pm 0.44$ & $0.99 \pm 0.61$ \\
\hline & CXCL12 & $0.89 \pm 0.17$ & $1.05 \pm 0.34$ & $1.67 \pm 0.50^{*}$ & $0.90 \pm 0.23$ & $1.35 \pm 0.48$ \\
\hline & CXCL13 & ND & $0.89 \pm 0.16$ & $5.66 \pm 4.27$ & $1.87 \pm 1.37$ & $0.84 \pm 0.21$ \\
\hline & CXCL14 & $0.78 \pm 0.25$ & $1.41 \pm 0.39$ & $5.12 \pm 2.69 *$ & $0.95 \pm 0.40$ & $0.42 \pm 0.38$ \\
\hline & CXCL15 & ND & ND & ND & $1.28 \pm 1.09$ & ND \\
\hline & CXCL16 & $2.17 \pm 1.00^{*}$ & $2.21 \pm 0.52 * *$ & $1.85 \pm 0.60^{*}$ & $2.26 \pm 0.35^{* * *}$ & ND \\
\hline & CXCL17 & ND & ND & ND & $11.69 \pm 6.52 *$ & $0.71 \pm 0.20$ \\
\hline $\mathrm{CX}_{3} \mathrm{C}$ chemokines & $\mathrm{CX}_{3} \mathrm{CL} 1$ & $0.84 \pm 0.46$ & $1.05 \pm 0.17$ & $3.45 \pm 1.82$ & $2.20 \pm 0.53^{* *}$ & $0.63 \pm 0.27$ \\
\hline $\mathrm{C}$ chemokines & XCL1 & ND & ND & $2.26 \pm 1.82$ & $0.94 \pm 0.38$ & $0.007 \pm 0.002^{* * *}$ \\
\hline
\end{tabular}

Male mice $(\mathrm{n}=5)$ were injected subcutaneously with methylmercuric chloride $(10 \mathrm{mg} / \mathrm{kg})$ for 7 consecutive days. Tissues were dissected 1 day after the last injection. Data show fold-changes in mRNA levels (mean \pm S.D.). $* P<0.05, * * P<0.01$, and $* P<$ 0.001 compared with controls. Data were analyzed using Student's t-test. ND: not detected. 
(A) CCL3
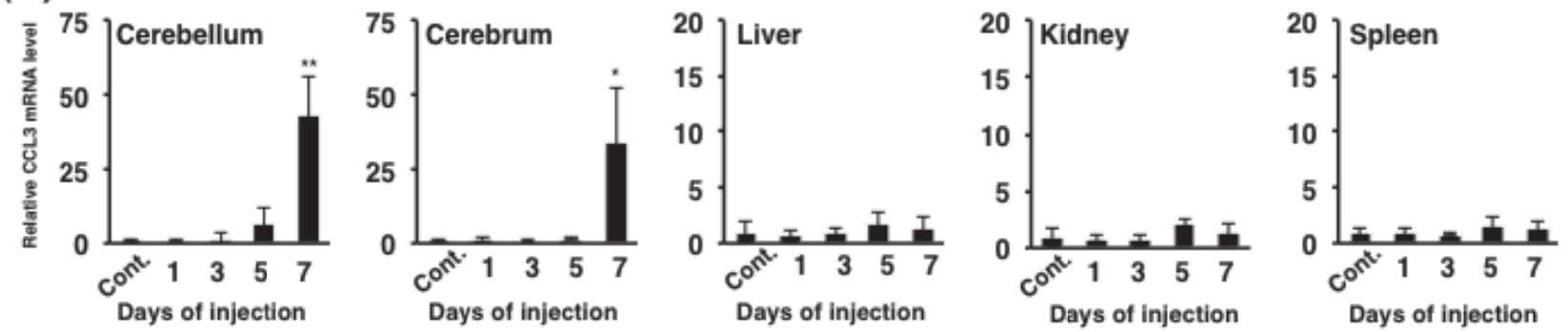

\section{(B) CCL4}
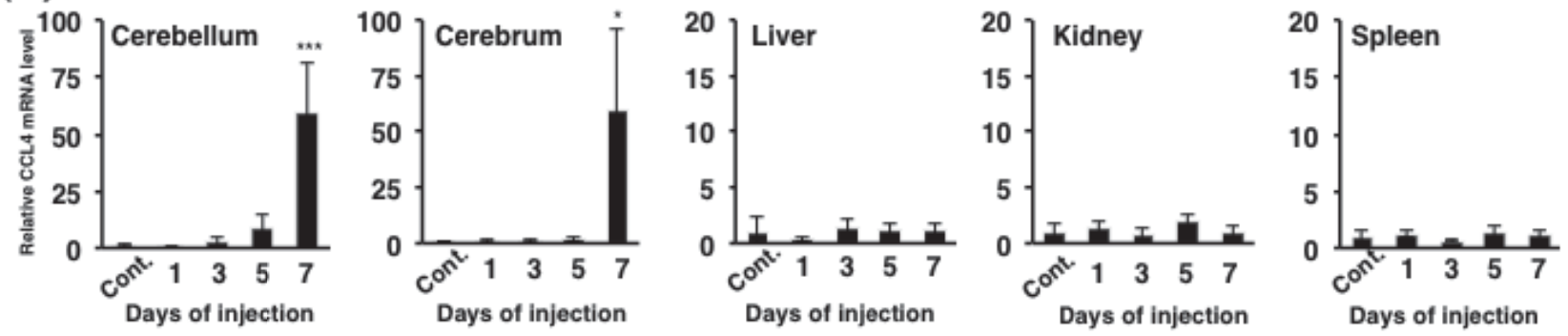

\section{(C) CXCL10}
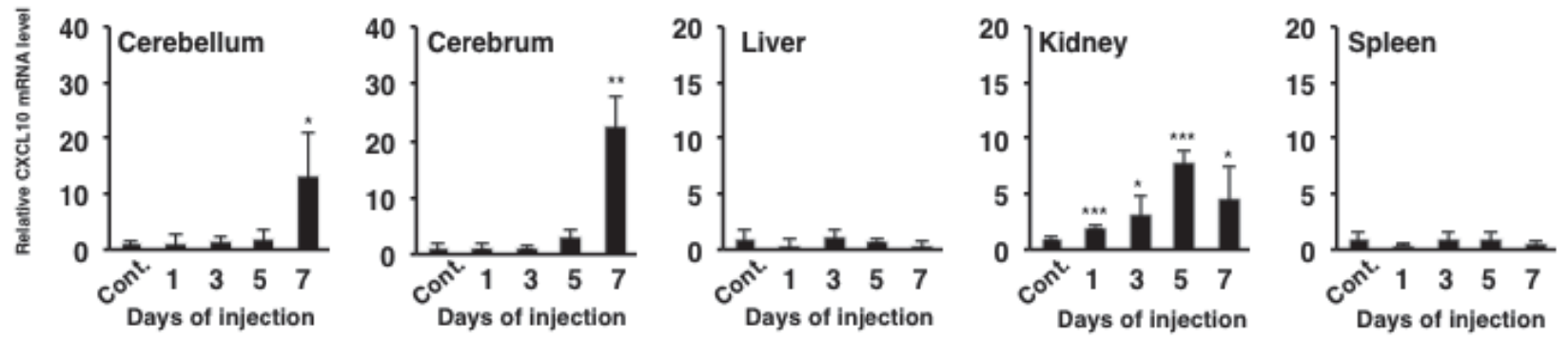

Fig. 1. Effects of multiple injections of methylmercury on the mRNA levels of CCL3, CCL4, and CXCL10 in various mouse tissues. Male mice $(\mathrm{n}=5)$ were injected subcutaneously with methylmercuric chloride $(10 \mathrm{mg} / \mathrm{kg} / \mathrm{day})$ daily for 7 consecutive days. Selected tissues were dissected 1 day after the first, third, fifth, and seventh injections. Levels of CCL3 (A), CCL4 (B), and CXCL10 (C) mRNA in the cerebellum, cerebrum, kidney, liver, and spleen were measured by quantitative real-time PCR in methylmercury-treated and control mice. mRNA levels were normalized to GAPDH levels. Data are presented as means \pm S.D. ${ }^{*} P<0.05,{ }^{*} P<0.01$, and $* * * P<0.001$ compared with the control group. Data were analyzed using Student's $t$-test.

Detailed elucidation of the mechanism underlying the methylmercury-induced upregulation of chemokine genes, such as CCL3 and CCL4, in the brain may provide important clues as to the mechanisms mediating the selective toxicity of methylmercury in the CNS.

\section{REFERENCES}

Castoldi, A.F., Coccini, T. and Manzo, L. (2003): Neurotoxic and molecular effects of methylmercury in humans. Rev. Environ. Health, 18, 19-31.

Gamo, K., Kiryu-Seo, S., Konishi, H., Aoki, S., Matsushima, K., Wada, K. and Kiyama, H. (2008): G-protein-coupled receptor screen reveals a role for chemokine receptor CCR5 in suppressing microglial neurotoxicity. J. Neurosci., 28, 11980-11988.

Giraud, S.N., Caron, C.M., Pham-Dinh, D., Kitabgi, P. and Nicot, A.B. (2010): Estradiol inhibits ongoing autoimmune neuroinflammation and NFkappaB-dependent CCL2 expression in reactive astrocytes. Proc. Natl. Acad. Sci. USA, 107, 8416-8421.

Gorter, J.A., van Vliet, E.A., Aronica, E., Breit, T., Rauwerda, H., Lopes da Silva, F.H. and Wadman, W.J. (2006): Potential new antiepileptogenic targets indicated by microarray analysis in a rat model for temporal lobe epilepsy. J. Neurosci., 26, 1108311110 .

Hwang, G.W., Lee, J.Y., Ryoke, K., Matsuyama, F., Kim, J.M., Takahashi, T. and Naganuma, A. (2011): Gene expression profiling using DNA microarray analysis of the cerebellum of mice treated with methylmercury. J. Toxicol. Sci., 36, 389-391. 


\section{(A) CCL3}
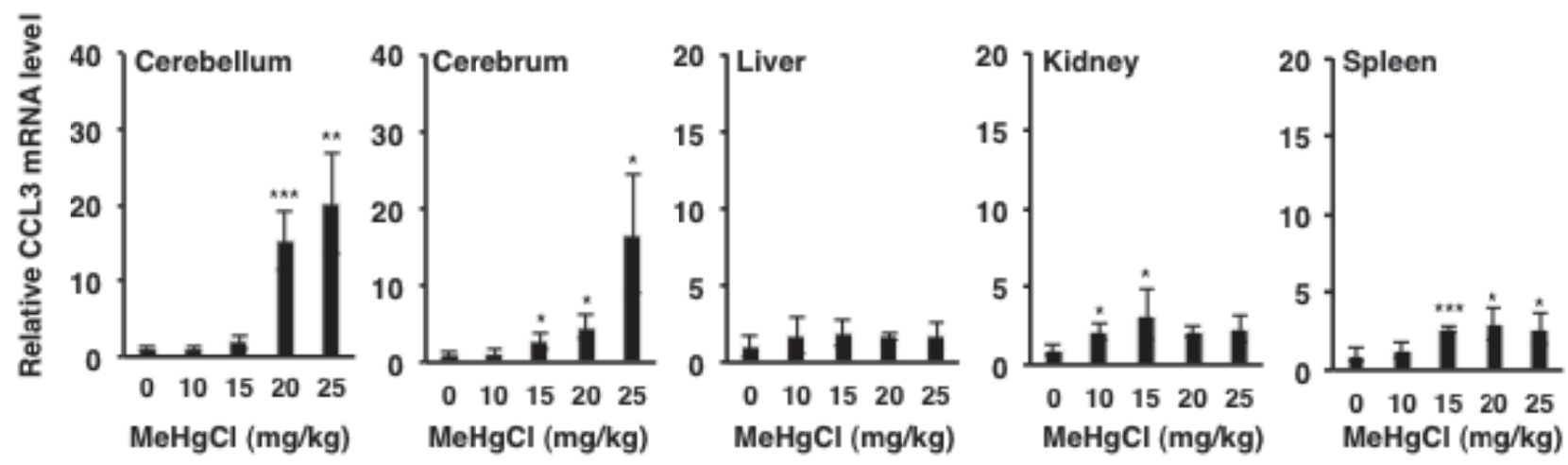

\section{(B) CCL4}
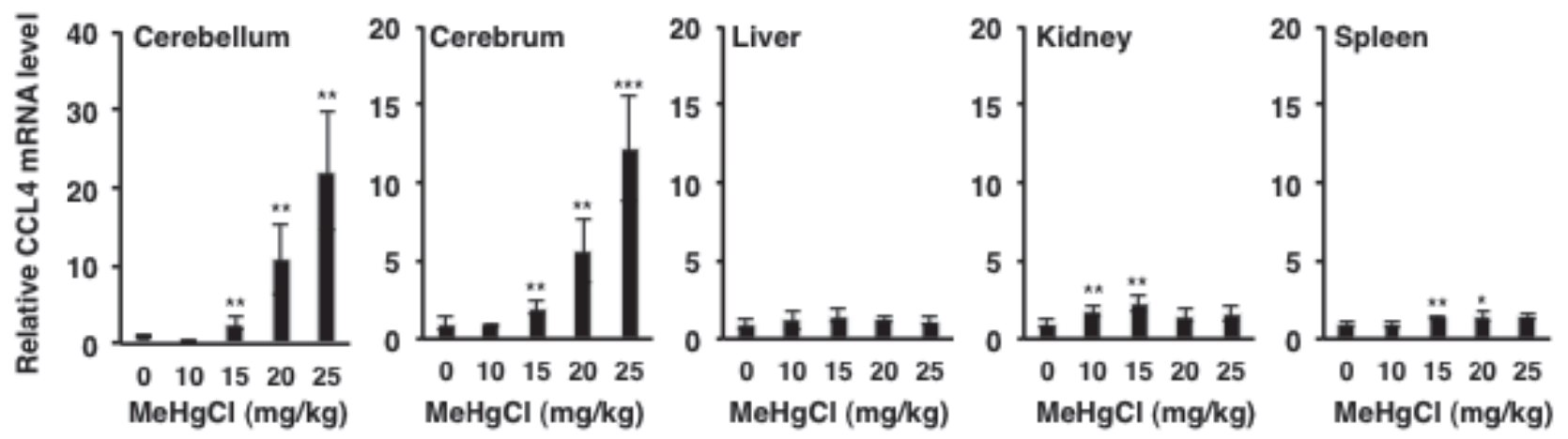

Fig. 2. Effects of a single injection of methylmercury on the mRNA levels of CCL3 and CCL4 in the cerebellum of mice. Male mice $(\mathrm{n}=5)$ were injected subcutaneously with methylmercuric chloride $(10,15,20$, or $25 \mathrm{mg} / \mathrm{kg})$. Five days later, the cerebellum, cerebrum, kidney, liver, and spleen were dissected, and the levels of CCL3 (A) and CCL4 (B) mRNA were analyzed by quantitative real-time PCR. For further details, see Fig. 1 legend.

Ito, S., Sawada, M., Haneda, M., Ishida, Y. and Isobe, K. (2006): Amyloid-beta peptides induce several chemokine mRNA expressions in the primary microglia and Ra2 cell line via the PI3K/ Akt and/or ERK pathway. Neurosci. Res., 56, 294-299.

Kim, M.S., Takahashi, T., Lee, J.Y., Hwang, G.W. and Naganuma, A. (2012): Methylmercury induces CCL2 expression through activation of NF-kappaB in human $1321 \mathrm{~N} 1$ astrocytes. J. Toxicol. Sci., 37, 1275-1278.

Lee, J.Y., Hwang, G.W., Kim, M.S., Takahashi, T. and Naganuma, A. (2012): Methylmercury induces a brain-specific increase in chemokine CCL4 expression in mice. J. Toxicol. Sci., 37, 12791282

Murdoch, C. and Finn, A. (2000): Chemokine receptors and their role in inflammation and infectious diseases. Blood, 95, 3032-
3043.

Redell, J.B., Moore, A.N., Grill, R.J., Johnson, D., Zhao, J., Liu, Y. and Dash, P.K. (2013): Analysis of functional pathways altered after mild traumatic brain injury. J. Neurotrauma, 30, 752-764.

Rollins, B.J. (1997): Chemokines. Blood, 90, 909-928.

Shimizu, H., Bolati, D., Higashiyama, Y., Nishijima, F., Shimizu, K. and Niwa, T. (2012): Indoxyl sulfate upregulates renal expression of MCP-1 via production of ROS and activation of NF-kappaB, p53, ERK, and JNK in proximal tubular cells. Life Sci., 90, 525-530.

Soria, G. and Ben-Baruch, A. (2008): The inflammatory chemokines CCL2 and CCL5 in breast cancer. Cancer Lett., 267, 271285. 